\section{Commentary: Nitric oxide and acute kidney injury: Understanding the puzzle of renal rescue after cardiac surgery}

\author{
John G. Augoustides, MD, FASE, FAHA
}

Acute kidney injury (AKI) is an independent predictor of significant morbidity and mortality after cardiac surgery. 1,2 Consequently, renal rescue is a priority in perioperative management. ${ }^{3}$ Unfortunately, knowledge gaps in the pathogenesis of AKI have persisted, prompting calls for magic bullets to help us understand this complex puzzle. . $^{4}$ One of the pieces in this puzzle is renal ischemia from multiple mechanisms, including depletion of nitric oxide due to endothelial dysfunction and hemolysis. ${ }^{7-10}$

The timely trial by Kamenshchikov and colleagues ${ }^{8}$ in this issue of the Journal has evaluated nitric oxide for renal rescue in elective adult cardiac surgery with cardiopulmonary bypass. In this trial, patients at moderate risk for AKI were randomized to nitric oxide therapy at a dose of 40 parts per million during cardiopulmonary bypass. ${ }^{8}$ Exposure to nitric oxide significantly decreased AKI and release of the renal injury biomarker, neutrophil gelatinase-associated lipocalin. ${ }^{8}$

How might these intriguing findings inform our approach to AKI? In a recent randomized trial from China $(\mathrm{N}=244)$, nitric oxide therapy during cardiopulmonary bypass and for the first 24 postoperative hours significantly reduced AKI throughout the first postoperative year. ${ }^{11}$ These convincing results have prompted a trial in the United States to evaluate whether these nephroprotective protects of nitric oxide are also relevant in the West. ${ }^{12}$ The data from Kamenshchikov

\footnotetext{
From the Cardiovascular and Thoracic Section, Department of Anesthesiology and Critical Care, Perelman School of Medicine, University of Pennsylvania, Philadelphia, Pa.

Dr Augoustides receives institutional support.

Disclosures: The author reported no conflicts of interest.

The Journal policy requires editors and reviewers to disclose conflicts of interest and to decline handling or reviewing manuscripts for which they may have a conflict of interest. The editors and reviewers of this article have no conflicts of interest.

Received for publication April 6, 2020; revisions received April 6, 2020; accepted for publication April 6, 2020; available ahead of print April 18, 2020.

Address for reprints: John G. Augoustides, MD, FASE, FAHA, Cardiovascular and Thoracic Section, Department of Anesthesiology and Critical Care, Dulles 680, HUP, 3400 Spruce St, Philadelphia, PA 19104-4283 (E-mail: yiandoc@hotmail. com).

J Thorac Cardiovasc Surg 2022;163:1404-5

0022-5223/\$36.00

Copyright (c) 2020 by The American Association for Thoracic Surgery

https://doi.org/10.1016/j.jtcvs.2020.04.031
}

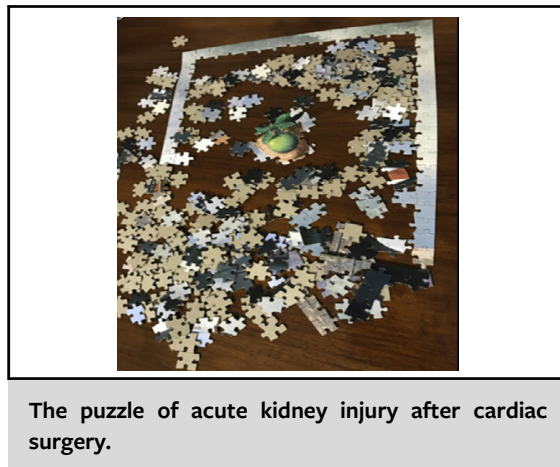

CENTRAL MESSAGE

Acute kidney injury after cardiac surgery is important. Nitric oxide therapy has great promise for renal rescue, helping us piece together the complex puzzle of acute kidney injury in this setting.

and colleagues therefore strengthen the hypothesis that nitric oxide protects the kidney after cardiac surgery, suggesting that renal rescue with nitric oxide may well be a generalizable perioperative intervention for our patients. ${ }^{8-11}$

What are our options in light of the literature? A recent meta-analysis $(\mathrm{N}=579: 5$ trials, including data from Kamenshchikov and colleagues) demonstrated that nitric oxide therapy significantly decreased the risk of AKI, especially when commenced early during cardiopulmonary bypass. ${ }^{13}$ Although the evidence to date is suggestive, further trials are required to clarify pharmacologic aspects of nitric oxide therapy for renal rescue such as dose, timing, and duration. ${ }^{7}$ 13

So, where do we go from here? There is a critical mass of positive data to support an adequately powered multicenter trial to test the potential for renal rescue with nitric oxide in cardiac surgery with cardiopulmonary bypass akin to the escalation of clinical trials for the evaluation of steroids in adult cardiac surgery. ${ }^{14}$ Given the promise of the nitric oxide trials to date and the central importance of AKI, the priority for a high-quality, large randomized trial may be an opportunity for the Cardiothoracic Surgery Trials Network. ${ }^{15}$ Further trials could also address not only the optimal perioperative dosing strategy for nitric oxide but also its nephroprotective potential in pediatric cardiac surgery (eg, one neonatal trial already listed-full details available at www.clinicaltrials.gov with trial identifier NCT03946462, last accessed April 5, 2020). 
In conclusion, Kamenshchikov and colleagues are to be congratulated for highlighting the promise of nitric oxide for renal protection in adult cardiac surgery. They have identified this versatile agent as a possible magic bullet for renal rescue as we continue our voyage to piece together the complex puzzle of AKI associated with cardiac surgery.

\section{References}

1. Engelman DT, Schwann TA. Commentary: a little is way too much: what we have learned about perioperative acute kidney injury. J Thorac Cardiovasc Surg. January 21, 2020 [Epub ahead of print].

2. Cho JS, Shim J, Lee S, Song JW, Choi N, Lee S, et al. Chronic progression of cardiac surgery associated acute kidney injury: intermediary role of acute kidney disease. J Thorac Cardiovasc Surg. November 6, 2019 [Epub ahead of print].

3. Kramer RS. Commentary: Is acute kidney injury after cardiac surgery the canary in the mineshaft? J Thorac Cardiovasc Surg. December 12, 2019 [Epub ahead of print].

4. Di Bacco L, Montisci A, Miceli A. Commentary: acute kidney injury: the onemillion pieces puzzle. J Thorac Cardiovasc Surg. 2019;157:2367-8.

5. Montisci A, Travaglini S, Miceli A. Commentary: the lack of a magic bullet. $J$ Thorac Cardiovasc Surg. 2019;157:2352-3.

6. Augoustides JG. Serum creatinine as a perioperative biomarker: a challenge for perioperative management and an opportunity for the Cardiothoracic Surgery Trials Network. J Thorac Cardiovasc Surg. 2012;143:523-4.
7. Chuey STH, Hwang NC. Acute kidney injury after cardiac surgery: a narrative review of the literature. J Cardiothorac Vasc Anesth. 2019;33:1122-38.

8. Kamenshchikov NO, Podoksenov YK, Anfinogenova YJ, Kozlov BN, Svirko YS, Pekarskiy SE, et al. Nitric oxide delivery during cardiopulmonary bypass reduces acute kidney injury: randomized trial. J Thorac Cardiovasc Surg. 2022;163:1393-403.e9.

9. Hessel EA. What's new in cardiopulmonary bypass? J Cardiothorac Vasc Anesth 2019;33:2296-326

10. Lama TT, Berra L, Zapol WM. The role of nitric oxide in preventing cardiopulmonary bypass-associated acute kidney injury. J Cardiothorac Vasc Anesth. 2020;34:850-1.

11. Lei C, Berra L, Rezoagli E, Yu B, Dong H, Yu S, et al. Nitric oxide decreases acute kidney injury and stage 3 chronic kidney disease after cardiac surgery. Am J Respir Care Crit Care Med. 2018;198:1279-87.

12. Marrazzo F, Spina S, Zadek F, Lama T, Xu C, Larson G, et al. Protocol of a randomized controlled trial in cardiac surgical patients with endothelial dysfunction aimed to prevent postoperative acute kidney injury by administering nitric oxide gas. BMJ Open. 2019;9:e026848.

13. Hi J, Spina S, Zadek F, Kamenshchikov NO, Bittner EA, Pedemonte J, et al. Effect of nitric oxide on postoperative acute kidney in patients who underwent cardiopulmonary bypass: a systematic review and meta-analysis with trial sequential analysis. Ann Intensive Care. 2019;9:129.

14. Crawford JH, Townsley MM. Steroids for adult and pediatric cardiac surgery: a clinical update. J Cardiothorac Vasc Anesth. 2019;33:2039-45.

15. Augoustides JG. Beating the clostridium difficile infection-insights from the Cardiothoracic Surgery Trials Network. J Thorac Cardiovasc Surg. 2017;155: 679-80.
See Article page 1393.

\section{Commentary: Just say NO!}

\author{
Jack S. Shanewise, MD, FASE
}

One nitrogen atom covalently bonded to 1 oxygen atom is nitric oxide. Add 1 more nitrogen and you have laughing gas-a medically useful compound produced by humans in large amounts. Add an oxygen atom to nitric oxide and you have smog-another gas produced by humans in abundance, unfortunately. Well known for many years to industrial chemical engineers, nitric oxide's biologic function as an important

From the Division of Cardiothoracic Anesthesiology, Vagelos College of Physicians \& Surgeons at Columbia University, New York, NY.

Disclosures: The author reported no conflicts of interest.

The Journal policy requires editors and reviewers to disclose conflicts of interest and to decline handling or reviewing manuscripts for which they may have a conflict of interest. The editors and reviewers of this article have no conflicts of interest.

Received for publication April 21, 2020; accepted for publication April 21, 2020; available ahead of print May 1, 2020.

Address for reprints: Jack S. Shanewise, MD, FASE, Division of Cardiothoracic Anesthesiology, Vagelos College of Physicians \& Surgeons at Columbia University, 622 W 168th St, PH5-505, New York, NY 10032 (E-mail: jss2128@ columbia.edu).

J Thorac Cardiovasc Surg 2022;163:1405-6

$0022-5223 / \$ 36.00$

Copyright (c) 2020 by The American Association for Thoracic Surgery

https://doi.org/10.1016/j.jtcvs.2020.04.068

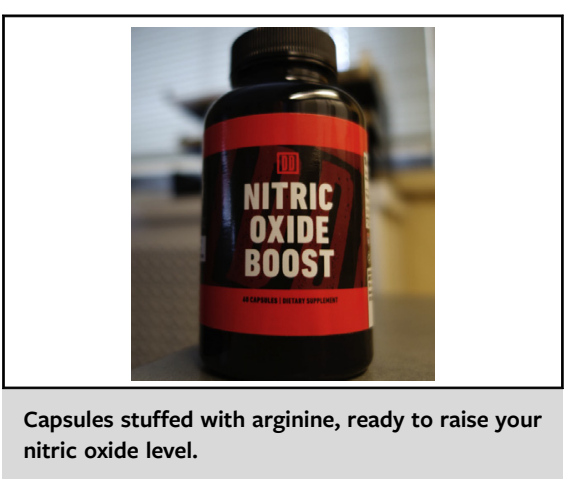

CENTRAL MESSAGE

Nitric oxide delivered through the oxygenator on CPB decreases AKI.

molecular signal in systems regulating vascular tone was elucidated in the 1980s, earning it Science magazine's "Molecule of the Year" award in 1992 and the 1998 Nobel Prize in Physiology or Medicine for 3 Americans: Furchott, Ignarro, and 